\title{
UNPAVED ROAD INFLUENCE AREAS IN HYDROCARBON EXPLORATION PROJECTS
}

\author{
MIGUEL ANTONIO DE LUQUE VILLA ${ }^{1} \&$ ALEXANDER VALENCIA CRUZ ${ }^{2}$ \\ ${ }^{1}$ Universidad de Cundinamarca, Colombia \\ ${ }^{2}$ CAIA INGENIERIA SAS, Colombia
}

\begin{abstract}
The influence area of a project includes environmental impacts caused by the development of the project on abiotic, biotic and socioeconomic components such as air, water, and soil. Knowing the location and extent of this area is essential for the environmental management of a project because it indicates where resources should be invested. This paper proposes a guide for the determination of areas of influence through the dispersion of particulate material in hydrocarbon projects. The present research looked at the unpaved road that leads from Puerto Gaitán (Meta, Colombia) to the Rubiales Field. The Gaussian dispersion model CALPUFF was used to determine the dispersion of particulate matter in the road section that connects Puerto Gaitán and the Rubiales field. 2000 discrete receptors were placed in a perpendicular line in three (3) sections of the road; these receptors were used to determine the concentration behaviour of particulate matter from the centre of the road every $2 \mathrm{~m}$, up to $2000 \mathrm{~m}$ on each side. In order to determine the concentration profiles of the particulate matter, the modelling results were plotted in Excel, and a correlation analysis was carried out between the meteorology, the road sections, the emission factors and the particulate matter dispersion. This information was adjusted to different types of probability distributions in order to determine the representative function of the behaviour of the concentrations which included all meteorological data. The distributions with the best fit of the data corresponded to the Beta distribution. A methodology was generated for the calculation of the influence area in unpaved roads for hydrocarbon exploration projects. The methodology was used for the environmental licensing process of the LLA-66 exploration area of the company BC exploration and production of hydrocarbons SL branch Colombia, located in the city of Puerto Lopez in the Department of Meta, Colombia. It was found that the area of influence extended $6 \mathrm{~m}$ to each side of the axis of the road.
\end{abstract}

Keywords: air pollution, influence areas, unpaved roads, hydrocarbon exploration projects, modelling.

\section{INTRODUCTION}

The mining energy sector in Colombia is one of the pillars of the government's development plan, which is why it is important to know to what extent air quality is affected when devising energy development strategies [1]. Many industrial activities, particularly energy, could be highly polluting and directly affect air quality and, consequently, human health [1]. In developing countries, dispersion models are increasingly being used and can be very useful in environmental impact assessments, as well as supporting the development of local action plans that improve air quality [2]. A project's area of influence includes environmental impacts caused by the development of the project on abiotic, biotic and socioeconomic components, such as air, water, and soil [3].

Knowing the location and extent of this area is essential for the environmental management of a project because it indicates where resources should be invested. This paper proposes a guide for the determination of areas of influence through the dispersion of particulate material of hydrocarbon projects, in which the transit of vehicles on unpaved roads is presented with the CALPUFF model [4]. 


\section{MATERIALS AND METHODS}

\subsection{Study area}

The present research looked at the unpaved road that leads from Puerto Gaitán (Meta, Colombia) to the Rubiales Field (Fig. 1).

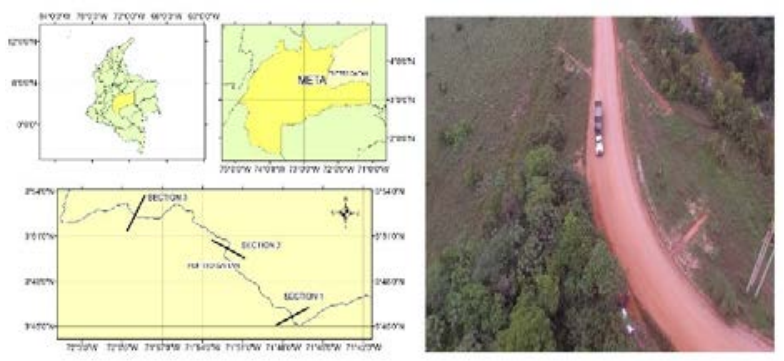

Figure 1: Puerto Gaitán - Rubiales field road.

\subsection{Emissions factors}

EPA guide AP-42, Chapter 13, miscellaneous sources (Section 13.2.2 - Unpaved roads) [5] was used to calculate the emission factors (eqn (1)).

$$
E_{F}=k\left(\frac{s}{12}\right)^{a}\left(\frac{W}{3}\right)^{b}
$$

where $\mathrm{k}, \mathrm{a}$, and $\mathrm{b}$ are empirical constants; $\mathrm{E}_{\mathrm{F}}=$ size-specific emission factor $(\mathrm{g} / \mathrm{VKT}) ; \mathrm{s}=$ surface material silt content (\%), (calculated granulometry by a carved mechanic [6]); $\mathrm{W}=$ mean vehicle weight (tons) $; \mathrm{VKT}=$ vehicle $\mathrm{km}$ travelled.

From the above, the values of the emission factors obtained are presented in Table 1.

Table 1: Unpaved road PST emission estimates parameters.

\begin{tabular}{|c|c|c|c|c|c|c|c|c|c|c|}
\hline Section & $\mathrm{s}(6)$ & $\mathrm{W}$ & $\mathrm{k}$ & $\mathrm{a}$ & $\mathrm{b}$ & $\begin{array}{c}\text { EF } \\
(\mathrm{g} / \mathrm{VKT})\end{array}$ & $\begin{array}{c}\text { Average } \\
\text { daily traffic } \\
(\text { vehicles/ } \\
\text { day })\end{array}$ & $\begin{array}{c}\text { Distance } \\
(\mathrm{km})\end{array}$ & $\mathrm{VKT}$ & $\begin{array}{c}\text { Particulate } \\
\text { matter } \\
\text { emission } \\
\left(\mathrm{g} / \mathrm{m}^{2} \mathrm{~s}\right)\end{array}$ \\
\hline 1 & 10.4 & 22 & 4.9 & 0.7 & 0.45 & 3063 & 980 & 40 & 33051.48 & 0.001160 \\
\hline 2 & 10.4 & 22 & 4.9 & 0.7 & 0.45 & 3063 & 525 & 40 & 17706.15 & 0.000630 \\
\hline 3 & 9.5 & 22 & 4.9 & 0.7 & 0.45 & 2875 & 14 & 40 & 472.16 & 0.000019 \\
\hline
\end{tabular}

\subsection{Air quality modelling}

The Gaussian dispersion model CALPUFF was used to determine the dispersion of particulate matter in the road section that connects Puerto Gaitán and the Rubiales field. The simulations were carried out under different meteorological conditions and emissions factors.

\subsubsection{Simulation scenarios}

To define the simulation scenarios, the available meteorology of the area and the emission factors of the road were taken into account. The topography was constant. The available 
meteorology for the study included data from the Rubiales Morelia Airport station for the year 2013. It was decided to simulate the entire year, separated month by month, resulting in 12 meteorological data sets, in order to increase the scenarios. In total, 39 scenarios were used.

\subsubsection{Topographic information}

It is necessary to process the topography in the dispersion model, a completely flat terrain is not assumed, using the Digital Elevation Model (DEM) on the area to be studied, which obtains the altitude relative to sea level of each source and receptor. For our study, we used the file 10s090w_20101117_gmted_mea075 from The Advanced Spaceborne Thermal Emission and Reflection Radiometer (ASTER) Global Digital Elevation Model (GDEM) [7], defining the coordinates in which it was necessary to import the elevations (Fig. 2).

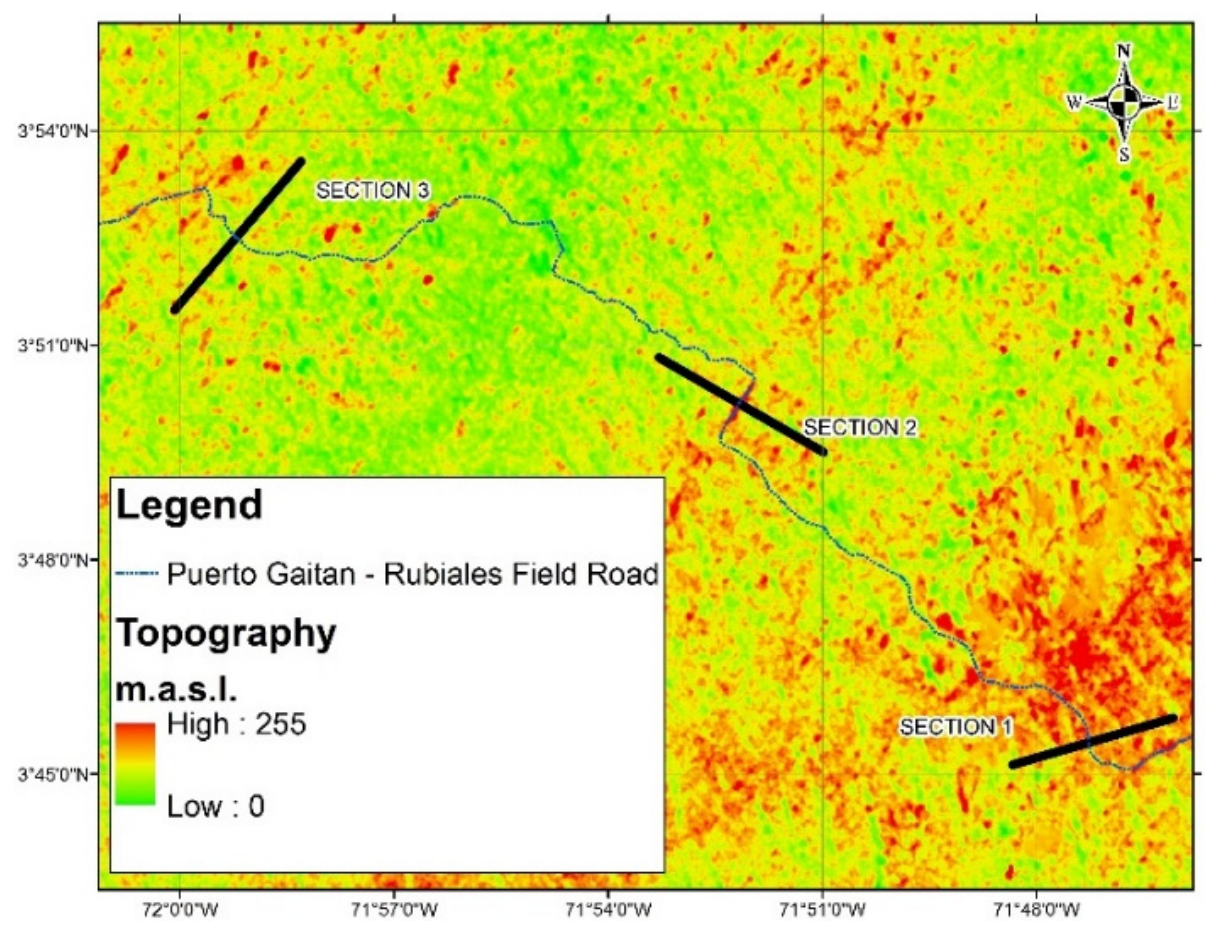

Figure 2: Study area topography.

\subsubsection{Meteorology information}

The wind rose representative of the analysed meteorology was obtained with the software WRPLOT View [8]; in this program, the values for wind speed and direction are set as input parameters. The result is shown in Fig. 3; the prevailing winds came from the east and northeast, and the predominant speeds were between 0.5 and $2.1 \mathrm{~m} / \mathrm{s}$.

\subsubsection{Modelling grid}

For the modelling domain, 10,000 receptors were distributed uniformly on a $40 \mathrm{~km} \times 40 \mathrm{~km}$ grid every $400 \mathrm{~m}$ to determine the global particulate distribution. Fig. 4 shows the location of the modelling grid. 


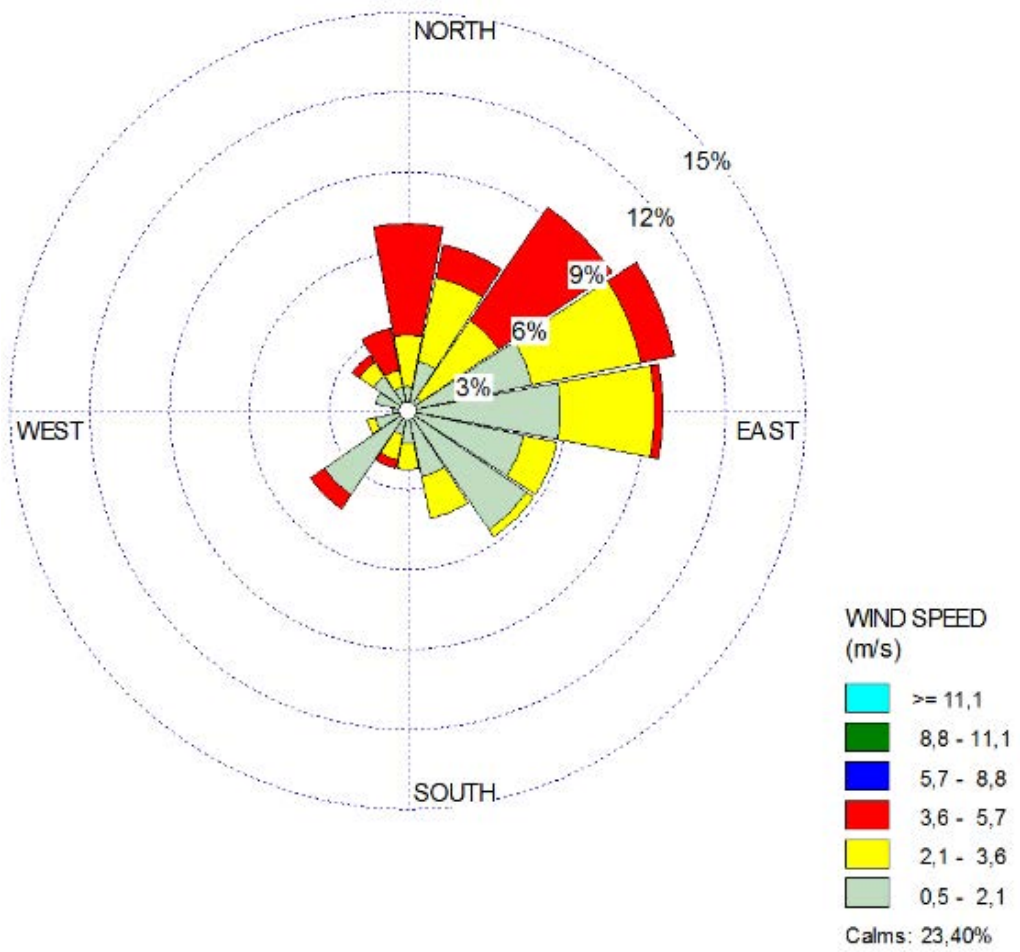

Figure 3: Wind rose Rubiales field.

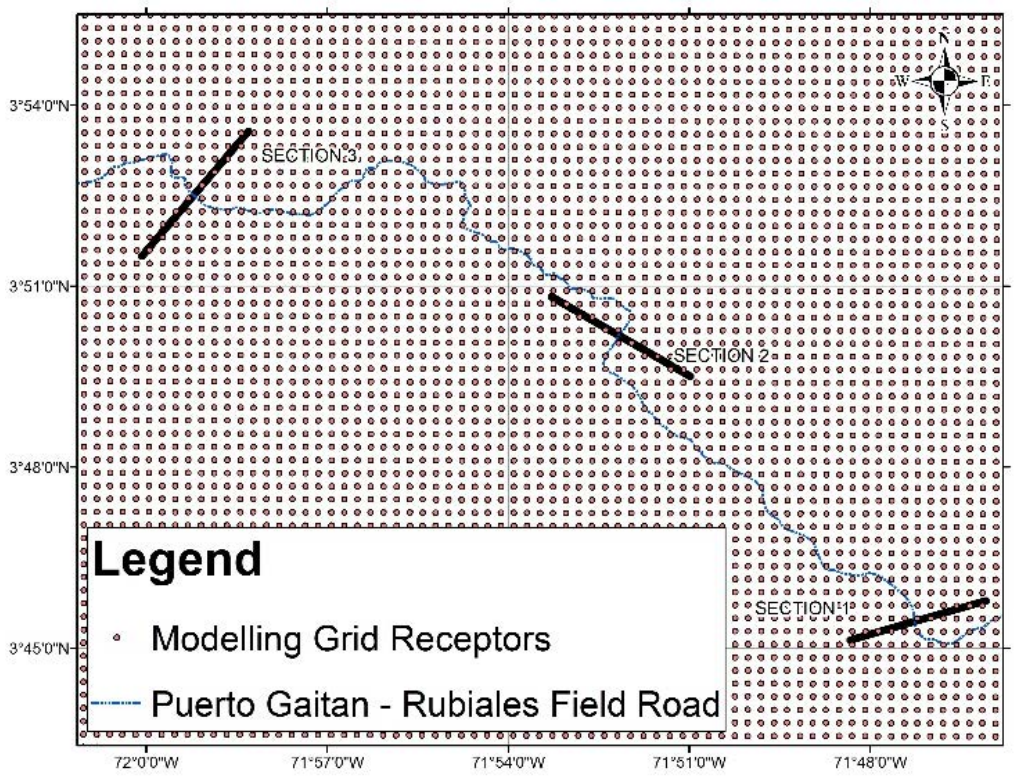

Figure 4: Modelling grid. 


\subsubsection{Discrete receptors}

2000 discrete receptors were placed in a perpendicular line in three sections of the road; these receptors were used to determine the decay of the concentrations on the sides of the road every $2 \mathrm{~m}$, up to $2000 \mathrm{~m}$ on each side. The location of the discrete receptors is shown in Fig. 5.

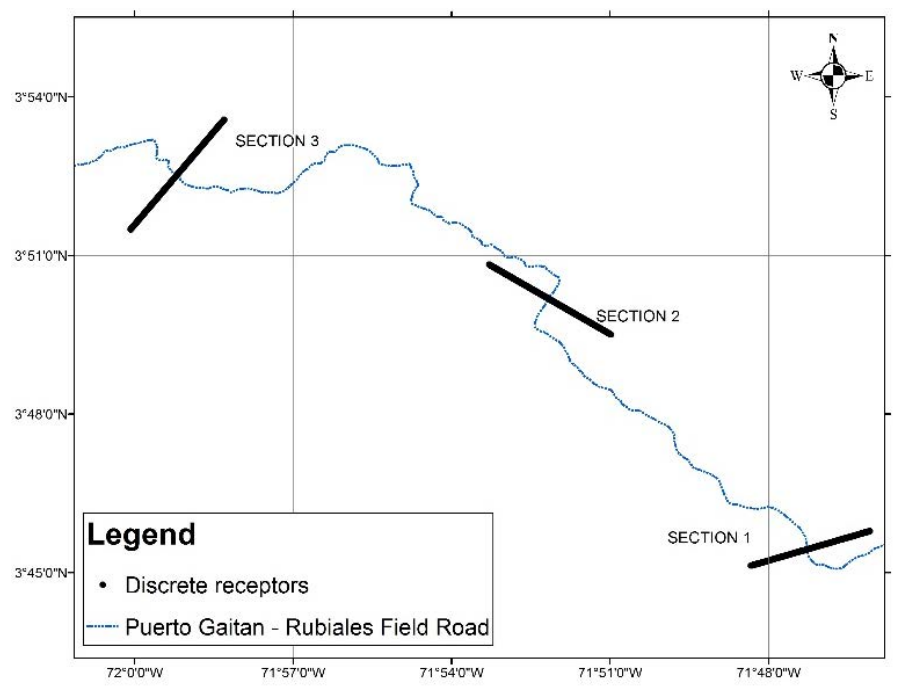

Figure 5: Discrete receptors Puerto Gaitán - Rubiales field road.

2.4 Identification of the probability density function adjusting to the behaviour of the particular matter

In order to determine the concentration profiles for the particulate matter, the modelling results were plotted in Excel, and a correlation analysis was carried out between the meteorology, the road sections and the emission factors and the particulate matter dispersion.

The results reported by the CALPUFF were processed to determine the average annual arithmetic concentrations. This information was adjusted to different types of probability distributions in order to generate a representative function of the behaviour of the concentrations, which included all meteorological data. This adjustment was made with the EasyFit distribution adjustment software [9], in which about 55 distributions were evaluated. EasyFit evaluates all available distributions in the literature using statistical goodness-of-fit tests (Chi-square, Kolmogorov-Smirnov and Anderson-Darling) and indicates the means of the p-value statistical parameter if the data conform to a given distribution. In this case, the goodness adjustment tests were defined with $95 \%$ confidence.

\section{RESULTS}

\subsection{Modelling results}

The modelling results in three different scenarios where the meteorology was similar, and the emission factors were different showed that the dispersion of particulate matter for the annual exposure period behaved similarly (Figs 6 and 7). 


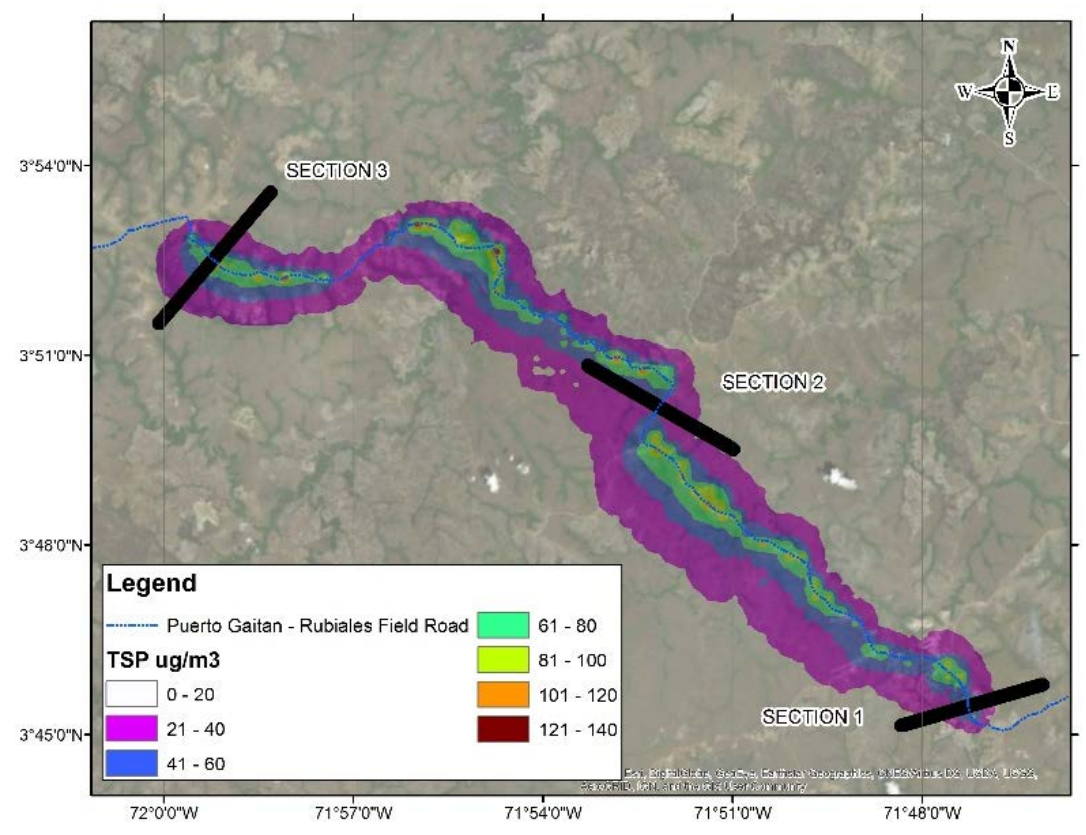

Figure 6: Concentration isopleths for the annual exposure period of particulate matter Scenario 1.

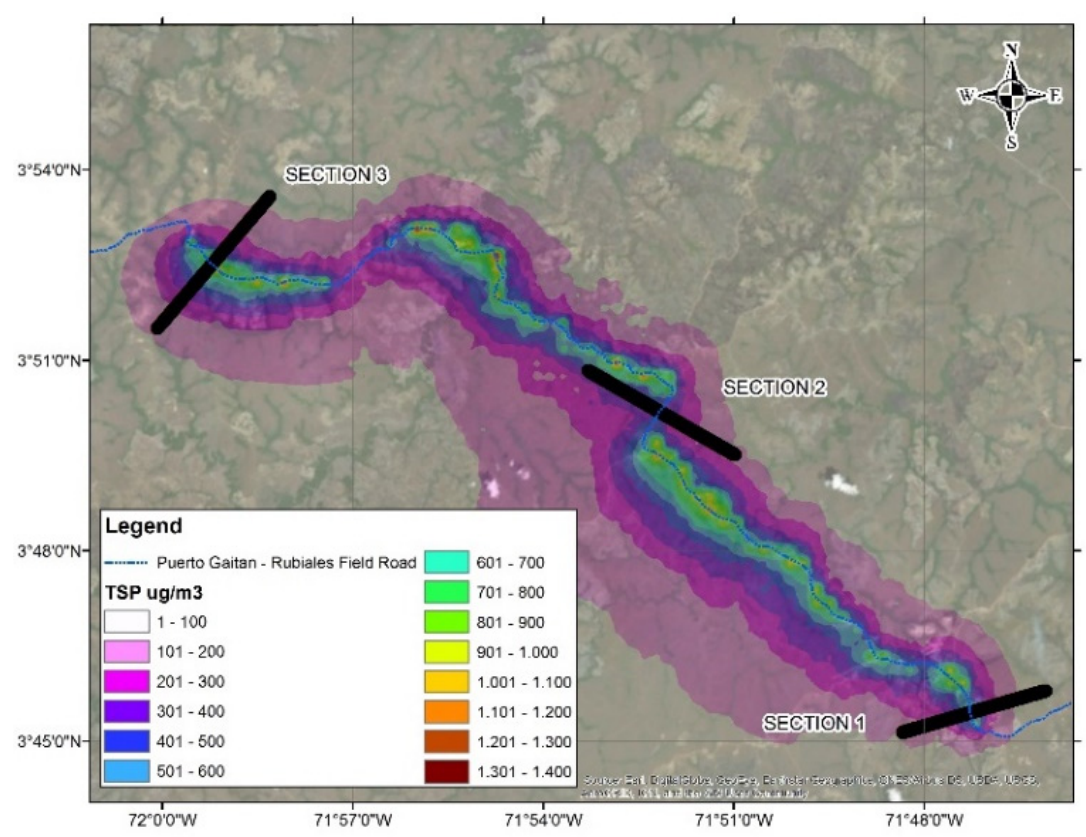

Figure 7: Concentration isopleths for the annual exposure period of particulate matter Scenario 2. 
The behaviour of the dispersion of particulate matter was similar in every section of the road, independent of the meteorology of the study area, and the air quality was directly proportional to the emission factor (Figs 8 and 9).

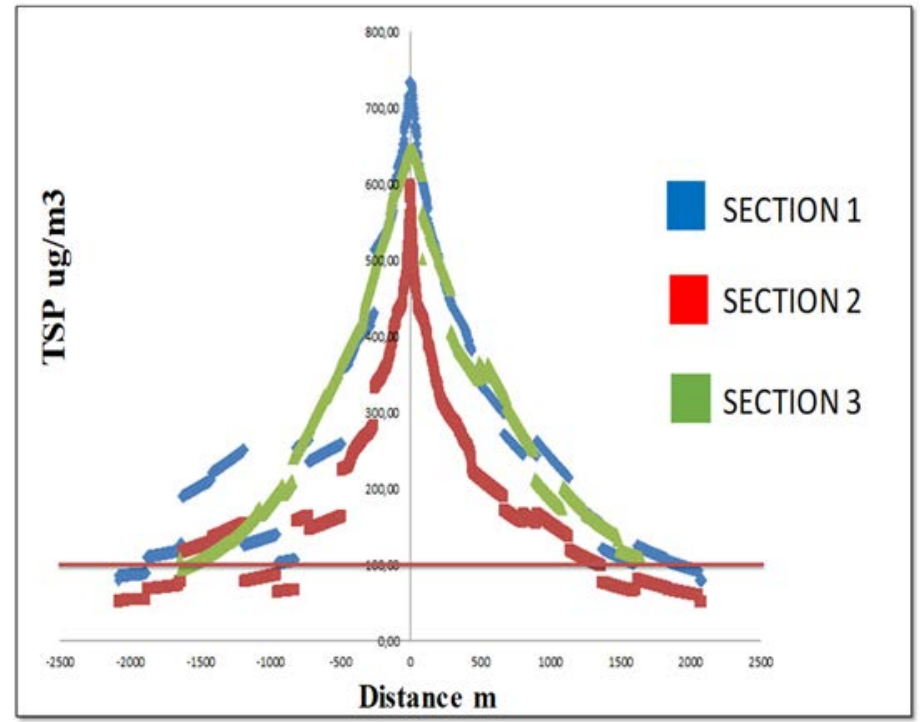

Figure 8: Average particulate matter concentration profiles for $2000 \mathrm{~m}$ on the side of the road Scenario 2.

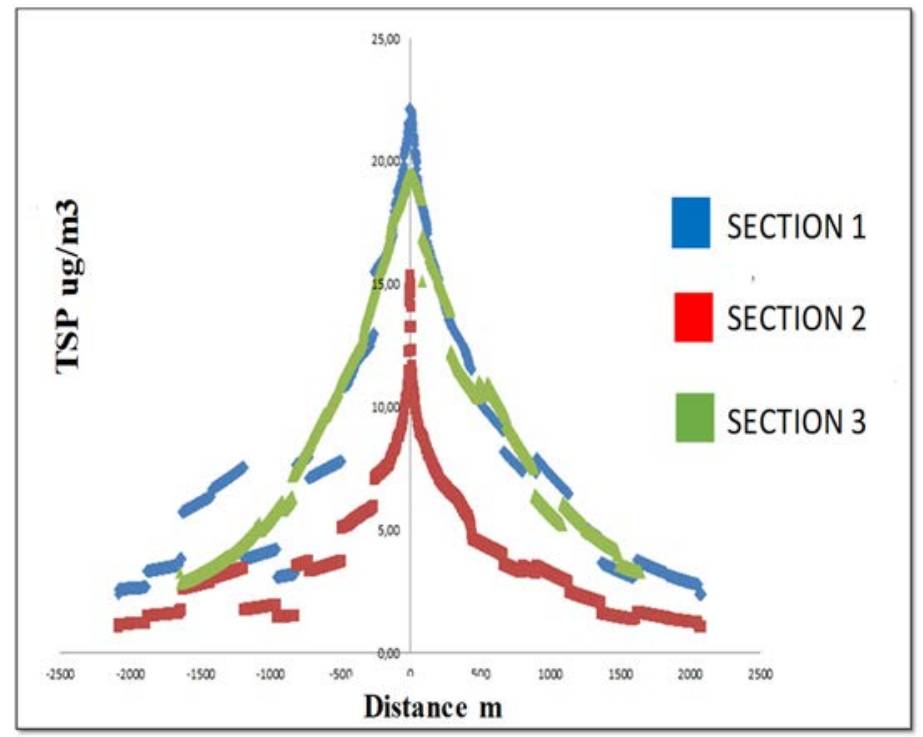

Figure 9: Average particulate matter concentration profiles for $2000 \mathrm{~m}$ on the side of the road Scenario 3. 
3.2 Adjustment of the probability density function for the behaviour of particular material

The results of the EasyFit Software indicated that the distributions with the best fit of the data corresponded to the Beta distribution (Fig. 10). Similar studies obtained the same distribution [10].

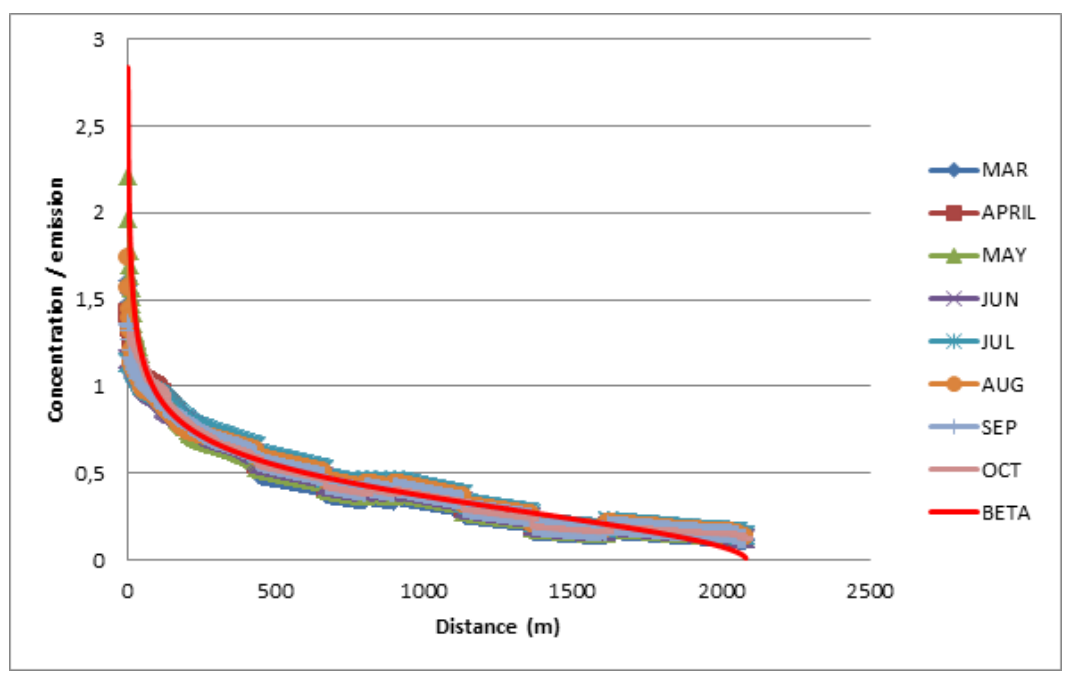

Figure 10: Adjustment of the beta distribution for concentrations of particulate matter.

3.3 Methodology to find the area of influence in unpaved roads in hydrocarbon exploration projects

Eqn (2) is proposed to determine the annual concentration of particulate matter.

$$
\mathrm{Ca}=\mathrm{Fa} \text { Beta }(\alpha 1, \alpha 2, \mathrm{~A}, \mathrm{~B}),
$$

where, $\mathrm{Ca}$ is the annual concentration in $\mu \mathrm{g} / \mathrm{m}^{3 ;} \mathrm{Fa}$ is the annual dispersion factor. Beta is the distribution function with parameters $\alpha 1, \alpha 2$. A and B represent minimum and maximum dispersion distances, respectively. Table 2 provides values for these parameters for TSP dispersion around unpaved roads.

Table 2: Beta distribution parameters.

\begin{tabular}{|l|c|c|c|c|c|}
\hline Parameter & Dispersion factor & $\alpha 1$ & $\alpha 2$ & $\mathrm{~A}$ & $\mathrm{~B}$ \\
\hline Particulate matter annual concentration & 834.74 & 0.726 & 1.567 & 0 & 2,085 \\
\hline
\end{tabular}

\subsection{Case study}

The methodology was used for the environmental licensing process of the LLA-66 exploration area of the company BC exploration and production of hydrocarbons SL branch Colombia, located in the city of Puerto Lopez in the Department of Meta, Colombia. It was found that the area of influence extended $6 \mathrm{~m}$ to each side of the axis of the road (Fig. 11). 


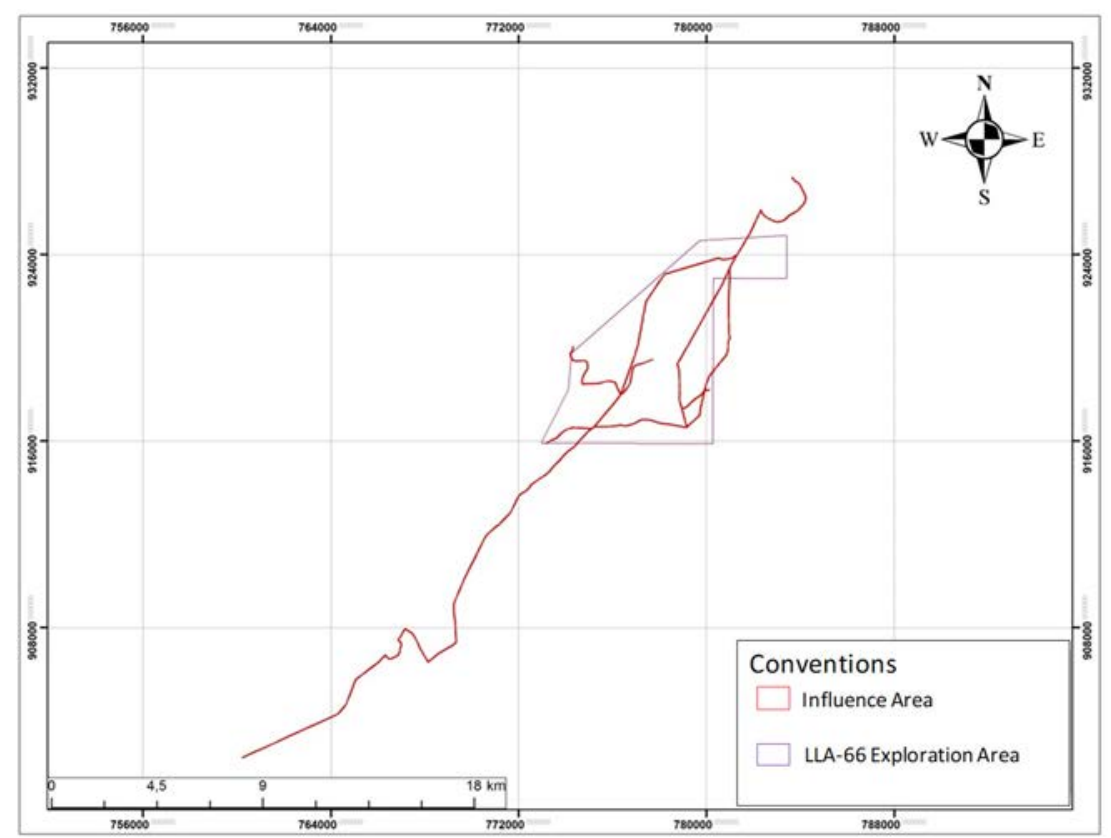

Figure 11: Area of influence on the atmospheric component LLA-66 exploration area.

\section{CONCLUSIONS}

According to the modelling results and distribution analysis performed in this study, we concluded that the decay of the particulate material on unpaved roads is adjusted to a beta distribution with the following parameters:

\section{ACKNOWLEDGEMENTS}

The authors thank the companies CAIA engineer and $\mathrm{BC}$ exploration and production of hydrocarbons SL branch Colombia for all of their support and information that they provided for the project.

\section{REFERENCES}

[1] Turtós, L., Modeling guide for the local dispersion of gaseous pollutants and particles with the AERMOD Model System, 2010.

[2] Conde, A.P., Local Action Plans to Improve Air Quality and Environmental Impact Studies Supported by Atmospheric Dispersion Models, National Congress of the Environment: Madrid, p. 21, 2008.

[3] ANLA. Autoridad Nacional de Licencias Ambientales. www.anla.gov.co/contenido/ contenido.aspx? catID=1324\&conID=7956. Accessed on: 26 May 2014.

[4] Scire, J., Strimaitis, D. \& Y.R.J., CALPUFF Dispersion Model, Earth Tech, Inc. 196 Baker Avenue Concord, MA 01742, no. January, 2000.

[5] US EPA, Emission Factor for Unpaved Road, US Environmental Protection Agency: Washington, 2001.

[6] Instituto Nacional de Vías, Granulometric analysis of soils by size. I.N.V. E - 123 07, 2007. 
[7] NASA LP DAAC, ASTER Level 1 Precision Terrain Corrected Registered At-Sensor Radiance. Version 3. NASA EOSDIS Land Processes DAAC, USGS Earth Resources Observation and Science (EROS) Center, Sioux Falls, South Dakota. https://lpdaac.usgs.gov. Accessed on: 1 Jan. 2016.

[8] Thé, J.L., Thé, C.L. \& Johnson, M.A., WRPLOT View Wind and Rain Rose Plots for Meteorological Data, 2016.

[9] Schittkowski, K., EASY-FIT: A software system for data fitting in dynamical systems EASY-FIT: A Software System for Data Fitting in Dynamic Systems. Structural and Multidisciplinary Optimization, 23(2), pp. 153-169, 2002.

[10] Huertas, M.E., Huertas, J.I., \& Valencia, A., Vehicular road influence areas. Atmospheric Environment, 151, pp. 108-116, 2017. 